\title{
Influence of Income on Cancer Incidence and Death among Patients in Aomori, Japan
}

\author{
Rina Tanaka ${ }^{1 *}$, Masashi Matsuzaka ${ }^{2}$, Yoshihiro Sasaki ${ }^{1,2}$
}

\begin{abstract}
Background: Aomori Prefecture has experienced the highest cancer-related mortality rates since the 2000s in Japan. In addition, income of residents in Aomori Prefecture is lower than that of a countrywide average. Aims of this study were to examine the relationships of the incidence and mortality rates of common cancers (stomach, colorectal, liver, lung, breast, cervical, and prostate) with the income levels of residential income area and clarify the factors contributing to the high mortality rates in Aomori prefecture.Methods: We included data on all patients diagnosed with stomach, colorectal, liver, lung, breast, cervical, or prostate cancer in the Aomori cancer registry database between 2010 and 2012. Age-standardized incidence rates and incidence rate ratios were calculated. Risk of cancer mortality related to economic disparities was determined via multivariable Cox regression analysis and adjusted for age, sex, and stage at diagnosis in the multivariable model. Results: We identified 21,240 eligible cancer patients. There were no differences in AIRs and IRRs among patients with stomach, colorectal, or lung cancer according to income. Contrarily, AIRs and IRRs were higher in higher-income areas than in lower-income areas among patients with breast, cervical, or prostate cancer. There were no significant differences in HRs according to income for any cancer type. Conclusions:Patients with higher income were diagnosed with early-stage disease more frequently, and they had higher AIRs for breast, cervical, and prostate cancers than those with middle and low incomes. However, there were no significant differences in hazard ratios.
\end{abstract}

Keywords: Incidence- mortality- socioeconomic status

Asian Pac J Cancer Prev, 19 (11), 3193-3202

\section{Introduction}

The incidence and mortality rates of stomach, liver, and cervical cancers are higher in lower-income countries than in higher-income countries (Ott et al., 2011). By contrast, those of lung, colorectal, and breast cancer are higher in higher-income countries (Torre et al., 2016). Individuals with higher levels of income and education are more likely to participate in cancer screening and treatment, thus explaining the lower rates of certain forms of cancer.

Meanwhile, risk factors for cancer include smoking, overweight and obesity, drinking, and certain chronic infections (Anand et al., 2008). Specifically, infections caused by Helicobacter pylori, human papillomavirus, and the hepatitis $\mathrm{B}$ and $\mathrm{C}$ viruses are the leading causes of stomach, cervical, and liver cancers, respectively (Oh et al., 2014). Previous studies reported that chronic infections are more likely to cause cancer in lower-income countries, further explaining differences in cancer incidence between lower- and higher-income nations (Ott et al., 2011; Bruni et al., 2016). Although the incidence of infection-related cancers declined in most higher-income countries, that of liver and stomach cancers is higher in Japan than in other countries (Ferlay et al., 2012).

In Japan, the overall incidence of cancer is increasing, and the disease has been a leading cause of death since 1981 (Vital statistics Japan). Specifically, the incidence of colorectal, lung, breast, pancreas, cervical, and prostate cancers has been increasing in Japan due to its aging society, although general cancer-related mortality has been decreasing (Vital statistics Japan). Some Japanese studies noted the inverse associations of cervical, endometrial, and colorectal cancer incidence and survival with area deprivation (Ueda et al., 2006; Miki et al., 2014). However, there have been few population-based studies of the association of area income with cancer death in Japan.

Aomori Prefecture has experienced the highest cancer-related mortality rates since the 2000s in Japan. Conversely, other prefectures successfully decreased cancer mortality rates. Thus, revealing the barriers to improving cancer-related mortality rates in Aomori Prefecture is of the utmost importance. It is assumed that access to hospitals and medical treatment may be an important factor in Aomori Prefecture because of its 
aging population and shortage of public transportation. In addition, the annual income of residents in Aomori Prefecture is lower than that of a countrywide average, $2,405,000$ yen vs. $3,057,000$ yen (System of National Accounts).

Aomori Prefecture consists of 40 municipal governments, and these regions have varied economic conditions (Supplement and supporting data). It is presumed that this inequality of economic conditions might be associated with cancer incidence and mortality. Therefore, the aims of this study were to examine the relationships of the incidence and mortality rates of common cancers (stomach, colorectal, liver, lung, breast, cervical, and prostate) in Japan with the income levels of the 40 municipalities in Aomori Prefecture and clarify the factors contributing to the high mortality rates in the prefecture.

\section{Materials and Methods}

\section{Patients}

We included data on all patients diagnosed with stomach, colorectal, liver, lung, breast, cervical, or prostate cancer in the Aomori cancer registry database between 2010 and 2012, and the patients were followed up until December 2013. Death certificate only (DCO) cases were excluded. The percentage of DCO cases $(\% \mathrm{DCO})$ is one of the quality indicators of cancer registry data, and the $\%$ DCO values of the Aomori cancer registry for 2010, 2011 , and 2012 were $5.1 \%, 2.6 \%$, and $2.0 \%$, respectively.

\section{Data collection}

We obtained the following clinical and demographic information via data extraction: sex, age at diagnosis, date of diagnosis, survival duration, primary tumor site (International Classification of Disease for Oncology, Third Edition; site code C16, C18-C20, C22, C33-C34, C50, C53, C61), stage at diagnosis, treatment administered (surgery, endoscopy, radiotherapy, chemotherapy, endocrine therapy, and other treatment), and address code. Stage at diagnosis was classified as in situ, localized (confined to the organ of origin), regional (invasion of adjacent organs or tissues and/or regional lymph node metastasis), distant (the presence of any distant metastasis), or unknown according to the Surveillance, Epidemiology, and End Results summary stage at diagnosis (Young et al., 2001). Income data for the 40 municipalities in 2010 were obtained from the Aomori Prefectural Government homepage (Municipal inhabitant's accounts statistics in Aomori prefecture), and income was classified into four groups by quartile as follows: lowest, mid-low, midhigh, and highest (Supplement and supporting data). The population of the municipalities in 2011-2012 was calculated using the interpolation method based on the population data of the National Census of Japan in 2010 and 2015 (National Census of Japan).

\section{Statistical analysis}

Age-standardized incidence rates (AIRs) were calculated using the direct method based on the Japanese standard population. The incidence rate ratios (IRRs) were calculated using the lowest income area as the reference. The risk of cancer mortality related to economic disparities was determined via multivariable Cox regression analysis and adjusted for age, sex, and stage at diagnosis in the multivariable model. Hazard ratios (HRs) were calculated using Stata 13 statistical software (StataCorp LLP, College Station, TX, USA).

\section{Results}

We identified 21,858 eligible patients, but the data for 618 patients were excluded for the following reasons: DCO, 616 cases; unknown address, 1 case; and unknown sex, 1 case.

Table 1 presents the characteristics of patients with various cancer. The proportions of patients with stomach or colorectal cancer who were diagnosed at early and late stages were similar among the income groups, although treatment was not equitable among the groups. The proportions of patients with stomach or colorectal cancer who were treated with surgery, radiotherapy, and chemotherapy were higher in higher-income areas than in lower-income areas. However, the proportion of patients with stomach cancer who were treated with endoscopic therapy was highest in the lowest income area. A higher proportion of patients with liver cancer received chemotherapy in higher-income areas than in lower-income areas. The proportion of patients who received other treatments (percutaneous ethanol injection therapy, radiofrequency ablation, and hepatic transcatheter arterial chemoembolization) was higher in higher-income areas than in lower-income areas. No significant differences in stage at diagnosis according to income were noted among patients with lung cancer. However, the proportion of patients with lung cancer who were treated with chemotherapy increased with increasing income. Meanwhile, the proportion of patients with breast cancer who were diagnosed at an early stage (in situ or localized) was higher in higher-income areas than in lower-income areas. Additionally, the proportions of patients with breast cancer who were treated with radiotherapy and endocrine therapy were highest in the highest income area. Among patients with cervical cancer, the proportion of patients who were diagnosed at an early stage (in situ or localized) was lowest in the lowest income area, and the proportion of patients treated with surgery was higher in higherincome areas than in lower-income areas. Conversely, the proportion of patients treated with chemotherapy was lower in lower-income areas. Among patients with prostate cancer, patients in the highest income group were most likely to be diagnosed at an early stage (localized). Additionally, the proportion of patients who received radiotherapy was higher in higher-income areas than in lower-income areas.

Table 2 shows the AIRs and IRRs by income and cancer type. Figure 1 shows scatter plot between AIRs and residential income. There were no differences in AIRs and IRRs among patients with stomach, colorectal, or lung cancer according to income. Contrarily, AIRs and IRRs were higher in higher-income areas than in lower-income areas among patients with breast, cervical, 
Table 1. Characteristics of Patients with Cancer

\begin{tabular}{|c|c|c|c|c|c|c|c|c|}
\hline \multirow{4}{*}{ Community income } & \multicolumn{8}{|c|}{ Stomach } \\
\hline & \multirow{2}{*}{\multicolumn{2}{|c|}{$\begin{array}{c}\text { Lowest } \\
n=496\end{array}$}} & \multirow{2}{*}{\multicolumn{2}{|c|}{$\begin{array}{c}\text { Mid-low } \\
n=583\end{array}$}} & \multirow{2}{*}{\multicolumn{2}{|c|}{$\begin{array}{l}\text { Mid-high } \\
\text { n=1297 }\end{array}$}} & \multirow{2}{*}{\multicolumn{2}{|c|}{$\begin{array}{l}\text { Highest } \\
n=1933\end{array}$}} \\
\hline & & & & & & & & \\
\hline & $\mathrm{N}$ & $\%$ & $\mathrm{~N}$ & $\%$ & $\mathrm{~N}$ & $\%$ & $\mathrm{~N}$ & $\%$ \\
\hline \multicolumn{9}{|l|}{ Sex } \\
\hline Men & 353 & 71.2 & 392 & 67.2 & 877 & 67.6 & 1,347 & 69.7 \\
\hline Women & 143 & 28.8 & 191 & 32.8 & 420 & 32.4 & 586 & 30.3 \\
\hline \multicolumn{9}{|l|}{ Age at diagnosis, years } \\
\hline-59 & 54 & 10.9 & 66 & 11.3 & 160 & 12.3 & 304 & 15.7 \\
\hline $60-69$ & 116 & 23.4 & 132 & 22.6 & 343 & 26.4 & 501 & 25.9 \\
\hline $70-79$ & 193 & 38.9 & 219 & 37.6 & 445 & 34.3 & 671 & 34.7 \\
\hline $80+$ & 133 & 26.8 & 166 & 28.5 & 349 & 26.9 & 457 & 23.6 \\
\hline \multicolumn{9}{|l|}{ Stage at diagnosis } \\
\hline In situ & 9 & 1.8 & 6 & 1.0 & 4 & 0.3 & 3 & 0.2 \\
\hline Localized & 237 & 47.8 & 266 & 45.6 & 598 & 46.1 & 833 & 43.1 \\
\hline Regional & 97 & 19.6 & 119 & 20.4 & 243 & 18.7 & 462 & 23.9 \\
\hline Distant & 90 & 18.1 & 126 & 21.6 & 282 & 21.7 & 428 & 22.1 \\
\hline Unknown & 63 & 12.7 & 66 & 11.3 & 170 & 13.1 & 207 & 10.7 \\
\hline \multicolumn{9}{|l|}{ Surgical treatment } \\
\hline Surgery & 214 & 43.1 & 280 & 48.0 & 631 & 48.7 & 969 & 50.1 \\
\hline Non-surgery & 235 & 47.4 & 274 & 47.0 & 593 & 45.7 & 871 & 45.1 \\
\hline Unknown & 47 & 9.5 & 29 & 5.0 & 73 & 5.6 & 93 & 4.8 \\
\hline \multicolumn{9}{|l|}{ Endoscopic therapy } \\
\hline Endoscopic therapy & 121 & 24.4 & 105 & 18.0 & 224 & 17.3 & 363 & 18.8 \\
\hline Non-endoscopic therapy & 333 & 67.1 & 447 & 76.7 & 994 & 76.6 & 1,473 & 76.2 \\
\hline Unknown & 42 & 8.5 & 31 & 5.3 & 79 & 6.1 & 97 & 5.0 \\
\hline \multicolumn{9}{|l|}{ Radiotherapy treatment } \\
\hline Radiotherapy & 1 & 0.2 & 5 & 0.9 & 12 & 0.9 & 17 & 0.9 \\
\hline Non-radiotherapy & 444 & 89.5 & 548 & 94 & 1,208 & 93.1 & 1,819 & 94.1 \\
\hline \multirow[t]{4}{*}{ Unknown } & 51 & 10.3 & 30 & 5.1 & 77 & 5.9 & 97 & 5.0 \\
\hline & \multicolumn{8}{|c|}{ Colorectal } \\
\hline & \multicolumn{2}{|c|}{ Lowest } & \multicolumn{2}{|c|}{ Mid-low } & \multicolumn{2}{|c|}{ Mid-high } & \multicolumn{2}{|c|}{ Highest } \\
\hline & \multicolumn{2}{|c|}{$\mathrm{n}=664$} & \multicolumn{2}{|c|}{$\mathrm{n}=810$} & \multicolumn{2}{|c|}{$\mathrm{n}=1885$} & $\mathrm{n}=3119$ & \\
\hline Sex & & & & & & & & \\
\hline Men & 382 & 57.5 & 483 & 59.6 & 1071 & 56.8 & 1785 & 57.2 \\
\hline Women & 282 & 42.5 & 327 & 40.4 & 814 & 43.2 & 1334 & 42.8 \\
\hline Age at diagnosis, years & & & & & & & & \\
\hline-59 & 121 & 18.2 & 108 & 13.3 & 338 & 17.9 & 514 & 16.5 \\
\hline $60-69$ & 154 & 23.2 & 213 & 26.3 & 501 & 26.6 & 879 & 28.2 \\
\hline $70-79$ & 219 & 33 & 293 & 36.2 & 620 & 32.9 & 1079 & 34.6 \\
\hline $80+$ & 170 & 25.6 & 196 & 24.2 & 426 & 22.6 & 647 & 20.7 \\
\hline Stage at diagnosis & & & & & & & & \\
\hline In situ & 139 & 20.9 & 166 & 20.5 & 341 & 18.1 & 620 & 19.9 \\
\hline Localized & 191 & 28.8 & 244 & 30.1 & 585 & 31 & 1032 & 33.1 \\
\hline Regional & 135 & 20.3 & 176 & 21.7 & 429 & 22.8 & 690 & 22.1 \\
\hline Distant & 104 & 15.7 & 148 & 18.3 & 334 & 17.7 & 515 & 16.5 \\
\hline Unknown & 95 & 14.3 & 76 & 9.4 & 196 & 10.4 & 262 & 8.4 \\
\hline
\end{tabular}




\begin{tabular}{|c|c|c|c|c|c|c|c|c|}
\hline \multirow{3}{*}{ Surgical treatment } & \multicolumn{8}{|c|}{ Colorectal } \\
\hline & \multirow{2}{*}{\multicolumn{2}{|c|}{$\begin{array}{c}\text { Lowest } \\
\mathrm{n}=664\end{array}$}} & \multirow{2}{*}{\multicolumn{2}{|c|}{$\begin{array}{l}\text { Mid-low } \\
n=810\end{array}$}} & \multirow{2}{*}{\multicolumn{2}{|c|}{$\begin{array}{c}\text { Mid-high } \\
\mathrm{n}=1,885\end{array}$}} & \multirow{2}{*}{\multicolumn{2}{|c|}{$\begin{array}{l}\text { Highest } \\
\mathrm{n}=3,119\end{array}$}} \\
\hline & & & & & & & & \\
\hline Surgery & 359 & 54.1 & 512 & 63.2 & 1,168 & 62.0 & 2,000 & 64.1 \\
\hline Non-surgery & 212 & 31.9 & 250 & 30.9 & 612 & 32.5 & 972 & 31.2 \\
\hline Unknown & 93 & 14.0 & 48 & 5.9 & 105 & 5.6 & 147 & 4.7 \\
\hline \multicolumn{9}{|l|}{ Endoscopic therapy } \\
\hline Endoscopic therapy & 169 & 25.5 & 166 & 20.5 & 404 & 21.4 & 721 & 23.1 \\
\hline Non-endoscopic therapy & 426 & 64.2 & 591 & 73.0 & 1,371 & 72.7 & 2229 & 71.5 \\
\hline Unknown & 69 & 10.4 & 53 & 6.5 & 110 & 5.8 & 169 & 5.4 \\
\hline \multicolumn{9}{|l|}{ Radiotherapy treatment } \\
\hline Radiotherapy & 2 & 0.3 & 3 & 0.4 & 12 & 0.6 & 27 & 0.9 \\
\hline Non-radiotherapy & 560 & 84.3 & 754 & 93.1 & 1758 & 93.3 & 2913 & 93.4 \\
\hline \multirow[t]{4}{*}{ Unknown } & 102 & 15.4 & 53 & 6.5 & 115 & 6.1 & 179 & 5.7 \\
\hline & \multicolumn{8}{|c|}{ Liver } \\
\hline & \multicolumn{2}{|c|}{ Lowest } & \multicolumn{2}{|c|}{ Mid-low } & \multicolumn{2}{|c|}{ Mid-high } & \multicolumn{2}{|c|}{ Highest } \\
\hline & $\mathrm{n}=124$ & & $\mathrm{n}=169$ & & $\mathrm{n}=433$ & & $\mathrm{n}=566$ & \\
\hline \multicolumn{9}{|l|}{ Sex } \\
\hline Men & 84 & 67.7 & 107 & 63.3 & 291 & 67.2 & 376 & 66.4 \\
\hline Women & 40 & 32.3 & 62 & 36.7 & 142 & 32.8 & 190 & 33.6 \\
\hline \multicolumn{9}{|l|}{ Age at diagnosis, years } \\
\hline-59 & 22 & 17.7 & 18 & 10.7 & 62 & 14.3 & 73 & 12.9 \\
\hline $60-69$ & 39 & 31.5 & 39 & 23.1 & 100 & 23.1 & 159 & 28.1 \\
\hline $70-79$ & 39 & 31.5 & 70 & 41.4 & 149 & 34.4 & 189 & 33.4 \\
\hline $80+$ & 24 & 19.4 & 42 & 24.9 & 122 & 28.2 & 145 & 25.6 \\
\hline \multicolumn{9}{|l|}{ Stage at diagnosis } \\
\hline Localized & 57 & 46 & 93 & 55 & 218 & 50.3 & 262 & 46.3 \\
\hline Regional & 17 & 13.7 & 27 & 16 & 81 & 18.7 & 101 & 17.8 \\
\hline Distant & 20 & 16.1 & 25 & 14.8 & 49 & 11.3 & 77 & 13.6 \\
\hline Unknown & 30 & 24.2 & 24 & 14.2 & 85 & 19.6 & 126 & 22.3 \\
\hline \multicolumn{9}{|l|}{ Surgical treatment } \\
\hline Surgery & 20 & 16.1 & 30 & 17.8 & 41 & 9.5 & 63 & 11.1 \\
\hline Non-surgery & 87 & 70.2 & 130 & 76.9 & 346 & 79.9 & 434 & 76.7 \\
\hline Unknown & 17 & 13.7 & 9 & 5.3 & 46 & 10.6 & 69 & 12.2 \\
\hline \multicolumn{9}{|l|}{ Radiotherapy treatment } \\
\hline Radiotherapy & 1 & 0.8 & 3 & 1.8 & 2 & 0.5 & 11 & 1.9 \\
\hline Non-radiotherapy & 106 & 85.5 & 157 & 92.9 & 385 & 88.9 & 484 & 85.5 \\
\hline Unknown & 17 & 13.7 & 9 & 5.3 & 46 & 10.6 & 71 & 12.5 \\
\hline \multicolumn{9}{|l|}{ Other treatment } \\
\hline Yes & 51 & 41.1 & 58 & 34.3 & 194 & 44.8 & 248 & 43.8 \\
\hline No & 56 & 45.2 & 102 & 60.4 & 193 & 44.6 & 248 & 43.8 \\
\hline Unknown & 17 & 13.7 & 9 & 5.3 & 46 & 10.6 & 70 & 12.4 \\
\hline
\end{tabular}


Table 1. Continued

\begin{tabular}{|c|c|c|c|c|c|c|c|c|}
\hline \multirow{3}{*}{ Sex } & \multicolumn{8}{|c|}{ Lung } \\
\hline & \multirow{2}{*}{\multicolumn{2}{|c|}{$\begin{array}{c}\text { Lowest } \\
\mathrm{n}=434\end{array}$}} & \multirow{2}{*}{\multicolumn{2}{|c|}{$\begin{array}{c}\text { Mid-low } \\
\mathrm{n}=472\end{array}$}} & \multirow{2}{*}{\multicolumn{2}{|c|}{$\begin{array}{l}\text { Mid-high } \\
n=1,062\end{array}$}} & \multirow{2}{*}{\multicolumn{2}{|c|}{$\begin{array}{l}\text { Highest } \\
n=1,700\end{array}$}} \\
\hline & & & & & & & & \\
\hline Men & 320 & 73.7 & 334 & 70.8 & 745 & 70.2 & 1,198 & 70.5 \\
\hline Women & 114 & 26.3 & 138 & 29.2 & 317 & 29.8 & 502 & 29.5 \\
\hline \multicolumn{9}{|c|}{ Age at diagnosis, years } \\
\hline-59 & 55 & 12.7 & 44 & 9.3 & 106 & 10 & 208 & 12.2 \\
\hline $60-69$ & 89 & 20.5 & 116 & 24.6 & 258 & 24.3 & 467 & 27.5 \\
\hline $70-79$ & 155 & 35.7 & 175 & 37.1 & 405 & 38.1 & 602 & 35.4 \\
\hline $80+$ & 135 & 31.1 & 137 & 29.0 & 293 & 27.6 & 423 & 24.9 \\
\hline \multicolumn{9}{|l|}{ Stage at diagnosis } \\
\hline In situ & 1 & 0.2 & 0 & 0.0 & 1 & 0.1 & 1 & 0.1 \\
\hline Localized & 105 & 24.2 & 110 & 23.3 & 198 & 18.6 & 391 & 23.0 \\
\hline Regional & 100 & 23.0 & 121 & 25.6 & 250 & 23.5 & 404 & 23.8 \\
\hline Distant & 152 & 35.0 & 169 & 35.8 & 437 & 41.1 & 642 & 37.8 \\
\hline Unknown & 76 & 17.5 & 72 & 15.3 & 176 & 16.6 & 262 & 15.4 \\
\hline \multicolumn{9}{|l|}{ Surgical treatment } \\
\hline Surgery & 90 & 20.7 & 98 & 20.8 & 207 & 19.5 & 439 & 25.8 \\
\hline Non-surgery & 293 & 67.5 & 326 & 69.1 & 745 & 70.2 & 1,100 & 64.7 \\
\hline Unknown & 51 & 11.8 & 48 & 10.2 & 110 & 10.4 & 161 & 9.5 \\
\hline \multicolumn{9}{|c|}{ Radiotherapy treatment } \\
\hline Radiotherapy & 108 & 24.9 & 116 & 24.6 & 214 & 20.2 & 416 & 24.5 \\
\hline Non-radiotherapy & 276 & 63.6 & 305 & 64.6 & 739 & 69.6 & 1122 & 66.0 \\
\hline \multirow[t]{4}{*}{ Unknown } & 50 & 11.5 & 51 & 10.8 & 109 & 10.3 & 162 & 9.5 \\
\hline & \multicolumn{8}{|c|}{ Breast } \\
\hline & \multirow{2}{*}{\multicolumn{2}{|c|}{$\begin{array}{c}\text { Lowest } \\
\mathrm{n}=186\end{array}$}} & \multirow{2}{*}{\multicolumn{2}{|c|}{$\begin{array}{c}\text { Mid-low } \\
\mathrm{n}=272\end{array}$}} & \multirow{2}{*}{\multicolumn{2}{|c|}{$\begin{array}{c}\text { Mid-high } \\
\mathrm{n}=711\end{array}$}} & \multirow{2}{*}{\multicolumn{2}{|c|}{$\begin{array}{l}\text { Highest } \\
\mathrm{n}=1,456\end{array}$}} \\
\hline & & & & & & & & \\
\hline \multicolumn{9}{|l|}{ Sex } \\
\hline Men & 2 & 1.1 & 3 & 1.1 & 4 & 0.6 & 12 & 0.8 \\
\hline Women & 184 & 98.9 & 269 & 98.9 & 707 & 99.4 & 1,444 & 99.2 \\
\hline \multicolumn{9}{|c|}{ Age at diagnosis, years } \\
\hline-59 & 84 & 45.2 & 143 & 52.6 & 362 & 50.9 & 750 & 51.5 \\
\hline $60-69$ & 45 & 24.2 & 70 & 25.7 & 181 & 25.5 & 366 & 25.1 \\
\hline $70-79$ & 36 & 19.4 & 42 & 15.4 & 108 & 15.2 & 225 & 15.5 \\
\hline $80+$ & 21 & 11.3 & 17 & 6.3 & 60 & 8.4 & 115 & 7.9 \\
\hline \multicolumn{9}{|l|}{ Stage at diagnosis } \\
\hline In situ & 15 & 8.1 & 15 & 5.5 & 75 & 10.5 & 132 & 9.1 \\
\hline Localized & 89 & 47.8 & 140 & 51.5 & 365 & 51.3 & 774 & 53.2 \\
\hline Regional & 52 & 28 & 70 & 25.7 & 169 & 23.8 & 366 & 25.1 \\
\hline Distant & 8 & 4.3 & 15 & 5.5 & 43 & 6 & 79 & 5.4 \\
\hline Unknown & 22 & 11.8 & 32 & 11.8 & 59 & 8.3 & 105 & 7.2 \\
\hline \multicolumn{9}{|l|}{ Surgical treatment } \\
\hline Surgery & 154 & 82.8 & 208 & 76.5 & 596 & 83.8 & 1179 & 81 \\
\hline Non-surgery & 16 & 8.6 & 40 & 14.7 & 79 & 11.1 & 201 & 13.8 \\
\hline Unknown & 16 & 8.6 & 24 & 8.8 & 36 & 5.1 & 76 & 5.2 \\
\hline Radiotherapy treatme & & & & & & & & \\
\hline Radiotherapy & 36 & 19.4 & 49 & 18 & 152 & 21.4 & 547 & 37.6 \\
\hline Non-radiotherapy & 134 & 72 & 197 & 72.4 & 522 & 73.4 & 828 & 56.9 \\
\hline Unknown & 16 & 8.6 & 26 & 9.6 & 37 & 5.2 & 81 & 5.6 \\
\hline
\end{tabular}




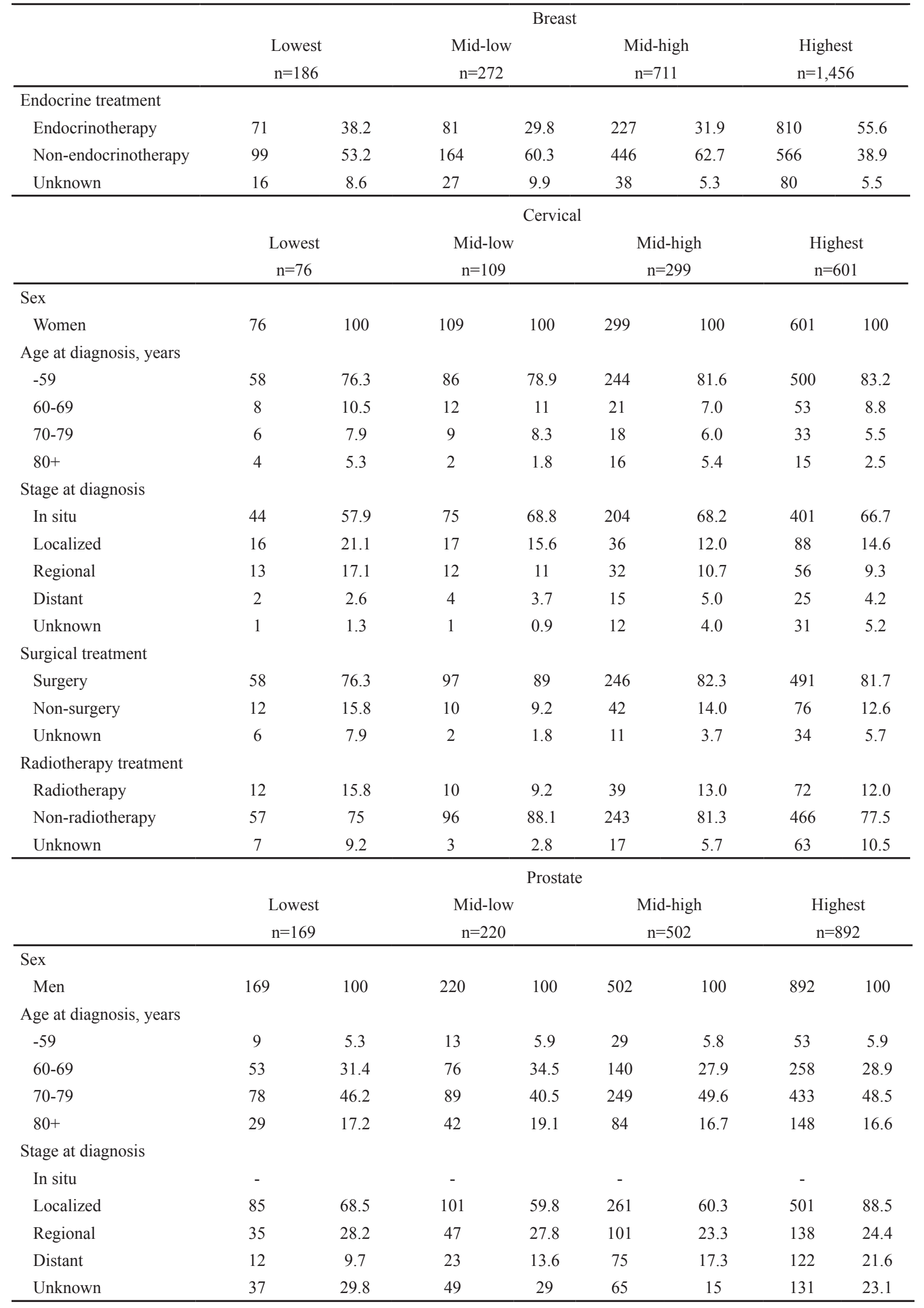




\begin{tabular}{|c|c|c|c|c|c|c|c|c|}
\hline & \multicolumn{8}{|c|}{ Prostate } \\
\hline & \multirow{2}{*}{\multicolumn{2}{|c|}{$\begin{array}{c}\text { Lowest } \\
\mathrm{n}=169\end{array}$}} & \multirow{2}{*}{\multicolumn{2}{|c|}{$\begin{array}{c}\text { Mid-low } \\
\mathrm{n}=220\end{array}$}} & \multirow{2}{*}{\multicolumn{2}{|c|}{$\begin{array}{c}\text { Mid-high } \\
\mathrm{n}=502\end{array}$}} & \multirow{2}{*}{\multicolumn{2}{|c|}{$\begin{array}{c}\text { Highest } \\
\mathrm{n}=892\end{array}$}} \\
\hline & & & & & & & & \\
\hline \multicolumn{6}{|l|}{ Surgical treatment } & & & \\
\hline Surgery & 53 & 31.4 & 56 & 25.5 & 126 & 25.1 & 228 & 25.6 \\
\hline Non-surgery & 87 & 51.5 & 124 & 56.4 & 319 & 63.5 & 537 & 60.2 \\
\hline Unknown & 29 & 17.2 & 40 & 18.2 & 57 & 11.4 & 127 & 14.2 \\
\hline \multicolumn{9}{|l|}{ Radiotherapy treatment } \\
\hline Radiotherapy & 20 & 11.8 & 32 & 14.5 & 104 & 20.7 & 165 & 18.5 \\
\hline Non-radiotherapy & 121 & 71.6 & 148 & 67.3 & 341 & 67.9 & 601 & 67.4 \\
\hline Unknown & 28 & 16.6 & 40 & 18.2 & 57 & 11.4 & 126 & 14.1 \\
\hline \multicolumn{9}{|l|}{ Endocrine treatment } \\
\hline Endocrinotherapy & 76 & 45 & 96 & 43.6 & 264 & 52.6 & 462 & 51.8 \\
\hline Non-endocrinotherapy & 69 & 40.8 & 85 & 38.6 & 182 & 36.3 & 308 & 34.5 \\
\hline Unknown & 24 & 14.2 & 39 & 17.7 & 56 & 11.2 & 122 & 13.7 \\
\hline
\end{tabular}

or prostate cancer.

Table 3 presents the adjusted HRs for each income category. Although the adjusted HRs tended to be highest in the lowest income area, there were no significant differences according to income for any cancer type.

\section{Discussion}

Certain chronic infections are risk factors for cancer, and they can explain variations in cancer incidence among low-, middle-, and high-income countries. A study by Ott et al. clearly indicated that the AIRs and mortality rates of lung, colorectal, and breast cancers were higher in high-income countries than in low- and middle-income countries (Ott et al., 2011). Moreover, they said that the AIRs and mortality rates of infection-related cancers (stomach, liver, and cervical cancers) were higher in low- and middle-income than in high-income countries (Ott et al., 2011). This can be explained by the fact that infection-related cancers account for more than $26 \%$ of

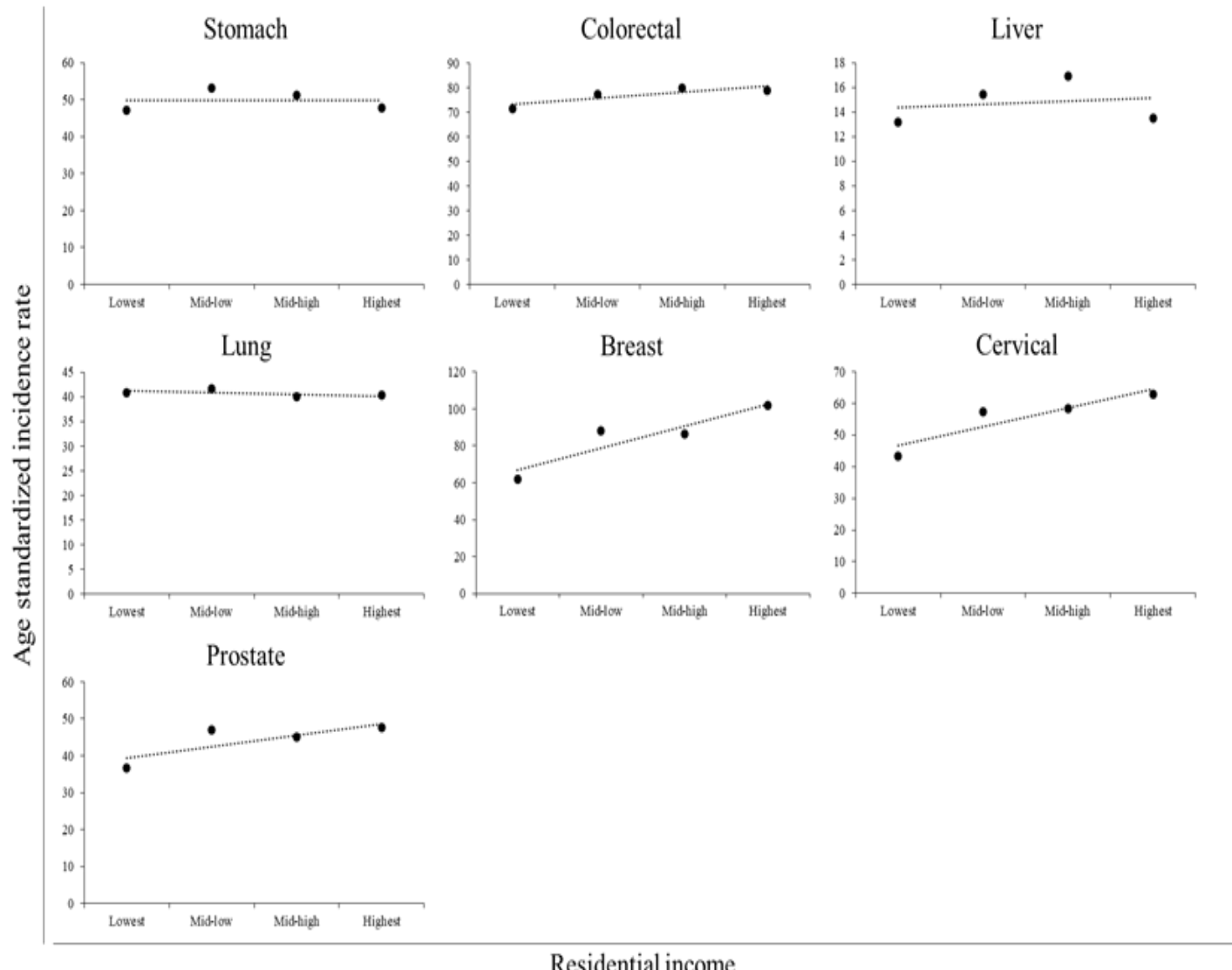

Figure 1. Scatter Plots between AIRs and Residential Income for Various Cancers 


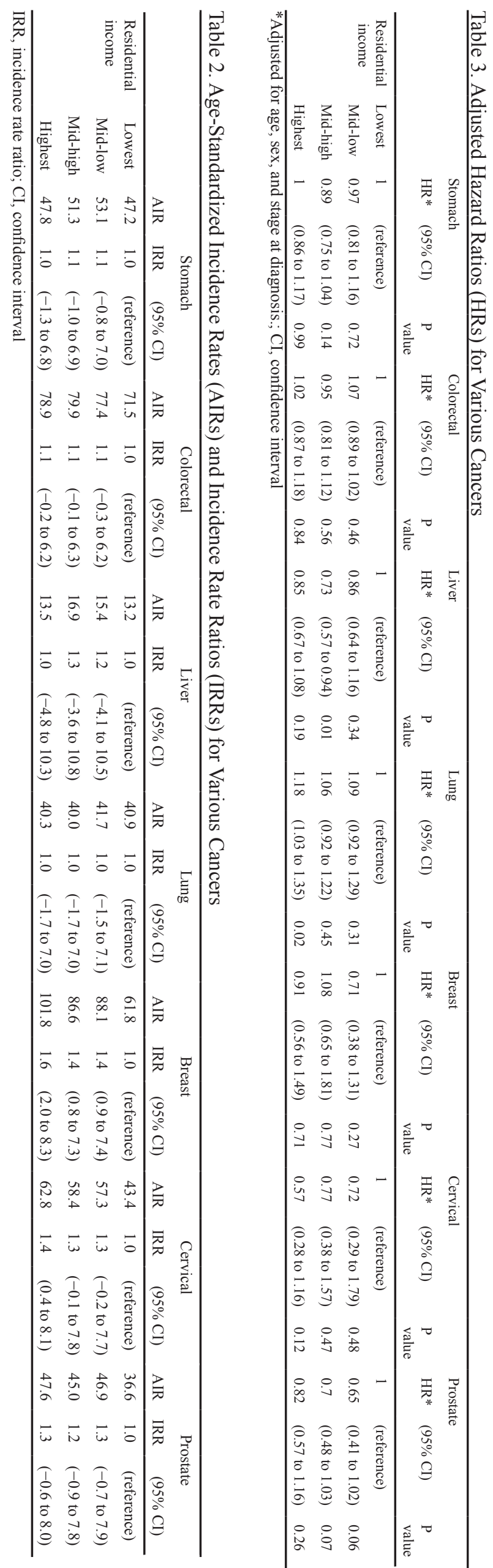

the total cancers in low- and middle-income countries (Parkin et al., 2006). Conversely, the incidence rate of non-infection-related cancers has continued to increase in many countries including high-, middle-, and lowincome countries (Global Burden of Disease Cancer Collaboration, et al., 2015). This unfavorable increase reflects an increased prevalence of known risk factors (e.g., obesity, physical inactivity, smoking) and the increased use of screening modalities (e.g., mammography, pap smear). Although mammography is the most effective method for detecting breast cancer at an early stage, it also leads to overdiagnosis of the disease (Marmot et al., 2013). A recent study that estimated that the rate of overdiagnosis due to mammography ranged $0 \%-54 \%$ (Puliti et al., 2011). By contrast, cancer-related mortality is affected by patients' access to cancer treatment. Because cancer treatment is not adequately accessible in low-income countries, cancer-related mortality rates have not declined in these countries (Fidler et al., 2017).

Our data identified disparities of AIRs for breast, cervical, and prostate cancers according to income, whereas those of stomach, colorectal, lung, and liver cancers were not influenced by income. However, the adjusted HRs were not significantly different according to income. Recent study investigated socioeconomic inequality in cancer mortality in South Korea (Khang et al., 2016). In this study, poor people had higher risk of cancer death. Although South Korea is similar to Japan, our results differed from previous study. These findings can be explained by several factors. First, the prevalence of risk factors for cervical, breast, and prostate cancers was higher in high-income areas than in middle- and low-income areas. Risk factors for these cancers include HPV infection, alcohol consumption habit, obesity, and aging (Key et al., 2002). In Aomori Prefecture, the average BMI among women was 23.2 in 2012, compared with a countrywide average of 22.5 (National Health and Nutrition Survey in 2012). In addition, $30.1 \%$ of people in Aomori Prefecture are older than 65, compared with $26.6 \%$ for the entire country (National Census of Japan). This higher proportion of elderly people might explain the findings in the prefecture. Second, because there were no significant differences in adjusted HRs according to age, overdiagnosis due to easy access to hospitals would increase the incidence rates and overtreatment for patients with breast, cervical, and prostate cancers simultaneously in higher-income areas. Several studies have underlined the problems of overdiagnosis and overtreatment (Nagler et al., 2017; Morgan et al., 2017; Jegerlehner et al., 2017). The Norwegian Breast Cancer Screening Program was conducted in 1995 and 1996 (Falk et al., 2013). This study reported the frequency of overdiagnosis among a cohort of women over a period of 10 years after they participated in cancer screening. Falk et al. estimated the number of women overdiagnosed in mammographic screening using English, Welsh, and Norwegian data (Falk et al., 2016). Moreover, Kilpeläinen et al., (2016) reported the association of prostate cancer with socioeconomic status in Finland. Their study found that higher socioeconomic status was associated with the overdiagnosis of low-risk 
prostate cancer, as well as a lower risk of incurable prostate cancer and lower prostate cancer-related mortality. Unnecessary treatment, higher treatment costs, and otiose anxiety might be burdensome to patients. Third, it was suspected that accessibility to cancer treatment was not significantly affected by residential income. Dreyer et al., (2017) reported socioeconomic disparities in the receipt of treatment for incident breast cancer. They observed that poor and near-poor women were less likely to receive treatment than women of a higher socioeconomic status. Kumachev et al., (2016) studied the associations among socioeconomic status, screening, and treatments. In this study, they demonstrated that higher socioeconomic status was associated with greater frequencies of screening and treatments and higher survival rates. Therefore, our results partially coincided with these previous findings. However, age standardized mortality rates for cancer in Aomori Prefecture are the highest in Japan. Thus, the quality of cancer treatment might not be sufficient to decrease the number of cancer-related deaths in this region.

Our study had several limitations. First, the income data do not exactly reflect patients' individual income. Our data reflected the average annual income in municipal areas. However, residential income might not reflect access to health and medical services for cancer because local governments have a responsibility to formulate cancer policy and ensure cancer control. Second, we did not include data for cancer risk factors at the individual level. Third, we did not include patients' individual educational levels and occupations. These socioeconomic factors have been examined to explain the disparities regarding cancer incidence and death. Because this study was designed to clarify the effect of income disparities on cancer, we did not include these data.

In conclusion, the relationships of mean residential income with cancer incidence and mortality differed from previous findings. Patients with higher income were diagnosed with early-stage disease more frequently, and they had higher AIRs for breast, cervical, and prostate cancers than those with middle and low incomes. However, there were no significant differences in cancer survival rates. Our results might be helpful for policymakers to develop a cancer policy. Policymakers should take steps HPV infection control and stopping excess prostatic specific antigen test in higher income area. Although the associations of socioeconomic status with cancer incidence and mortality have been reported for developed countries, socioeconomic disparities exist among individual areas in the countries. The differences in cancer mortality rates between affluent and poor individuals have reportedly widened in high-income countries. Thus, inequalities of cancer mortality rates between affluent and poor areas should be also investigated.

\section{Conflict of interest}

The authors declare no conflicts of interest associated with this manuscript.

\section{Reference}

Anand P, Kunnumakkara AB, Sundaram C, et al (2008). Cancer is a preventable disease that requires major lifestyle changes. Pharm Res, 25, 2097-116.

Bruni L, Diaz M, Barrionuevo-Rosas L, et al (2016). Global estimates of human papillomavirus vaccination coverage by region and income level: a pooled analysis. Lancet Glob Health, 4, 453-63.

Dreyer MS, Nattinger AB, Mc Ginley EL, et al (2017). Socioeconomic status and breast cancer treatment. Breast Cancer Res Treat (Epub ahead of print). doi: 10.1007/ s10549-017-4490-3.

Falk RS, Hofvind S, Skaane P, et al (2013). Overdiagnosis among women attending a population-based mammography screening program. Int $J$ Cancer, 133, 705-12.

Falk RS, Hofvind S. (2016). Overdiagnosis in mammographic screening because of competing risk of death. Cancer Epidemiol Biomarkers Prev, 25, 759-65.

Ferlay J, Soerjomataram I, Ervik M, et al (2012). GLOBOCAN 2012 v1.0, Cancer Incidence and Mortality Worldwide: IARC CancerBase No. 11. http://globocan.iarc.fr Accessed Nov 2017.

Global Burden of Disease Cancer Collaboration, Fitzmaurice C, Dicker D, et al (2015). The global burden of cancer 2013. JAMA Oncol 1:505-27.

Jegerlehner S, Bulliard JL, Aujesky D, et al (2017). Overdiagnosis and overtreatment of thyroid cancer: a population-based temporal trend study. PLoS One, 12, e0179387. doi: 10.1371/ journal.pone.0179387.

Key TJ, Allen NE, Spencer EA, et al (2002). The effect of diet on risk of cancer. Lancet, 360, 861-8.

Khang YH, Kim HR (2016). Socioeconomic inequality in mortality using 12-year follow-up data from nationally representative surveys in South Korea. Int J Equity Health, $15,51$.

Kilpeläinen TP, Talala K, Raitanen J, et al (2016). Prostate cancer and socioeconomic status in the Finnish randomized study of screening for prostate cancer. Am J Epidemiol (Epub ahead of print).

Kumachev A, Trudeau ME, Chen KK (2016). Associations among socioeconomic status, patterns of care and outcomes in breast cancer patients in a universal health care system: Ontario's experience. Cancer, 122, 893-8.

Nagler RH, Franklin Fowler E, Gollust SE (2017). Women's awareness of and responses to messages about breast cancer overdiagnosis and overtreatment: results from a 2016 national survey. Med Care, 55, 879-85.

National Census of Japan, (Ministry of Internal Affairs and Communications, Statistics Bureau) (in Japanese). http:// www.e-stat.go.jp/SG1/estat/GL08020103.do? toGL08020 103_\&tclassID $=000001077438 \&$ cycleCode $=0$ \& requestSe nder $=$ estat Accessed Nov 2017.

National Health and Nutrition Survey in 2012 (Ministry of Health, Labour and Welfare), (in Japanese). http://www. mhlw.go.jp/bunya/kenkou/eiyou/h24-houkoku.html Accessed Nov 2017.

Marmot MG, Altman DG, Cameron DA, et al (2013). The benefits and harms of breast cancer screening: an independent review. Br J Cancer, 108, 2205-40.

Miki Y, Inoue M, Ikeda A, et al (2014). Neighborhood deprivation and risk of cancer incidence, mortality and survival: results from a population-based cohort study in Japan. PLoS One, 9, e106729.

Morgan DJ, Dhruva SS, Coon ER, et al (2017). 2017 update on medical overuse: a systematic review. JAMA Interm Med (in press). doi: 10.1001/jamainternmed.2017.4361.

Municipal inhabitant's accounts statistics in Aomori prefecture, Aomori Prefectural Government (in Japanese). http://www6. pref.aomori.lg.jp/tokei/data/0000003207/0000003207_2_3. 
xlsx Accessed Nov 2017.

Oh JK, Weiderpass E (2014). Infection and cancer: global distribution and burden of diseases. Ann Glob Health, 80, 384-92.

Ott JJ, Ullrich A, Mascarenhas M, et al (2011). Global cancer incidence and mortality caused by behavior and infection. $J$ Public Health, 33, 223-33.

Parkin DM (2006). The global health burden of infection-associated cancers in the year 2002. Int J Cancer, 118, 30-44.

Puliti D, Miccinesi G, Paci E (2011). Overdiagnosis in breast cancer: design and methods of estimation in observational studies. Prev Med, 53, 131-3.

System of National Accounts (Cabinet Office, Government of Japan) (in Japanese). http://www.esri.cao.go.jp/jp/sna/ data/data_list/kenmin/files/files_kenmin.html Accessed Nov 2017.

Torre LA, Siegel RL, Ward EM, et al (2016). Global cancer incidence and mortality rates and trends-An update. Cancer Epidemiol Biomarkers Prev, 25, 16-27.

Ueda K, Kawachi I, Tsukuma H (2006). Cervical and corpus cancer survival disparities by socioeconomic status in a metropolitan area of Japan. Cancer Sci, 97, 283-91.

Vital statistics Japan (Ministry of Health, Labour and Welfare). http://www.e-stat.go.jp/SG1/estat/List. do?lid=000001108740 Accessed Nov 2017.

Vital Statistics Japan (Ministry of Health, Labour and Welfare), Cancer Registry and Statistics. Cancer Information Service, National Cancer Center, Japan. http://ganjoho.jp/reg_stat/ statistics/dl/index.html Accessed Nov 2017.

Young JL Jr, Roffers SD, Ries LAG, et al (2001). SEER Summary staging manual - 2000 : codes and coding instructions. National Cancer Institute, NIH Pub. No. 01-4969, Bethesda, MD.

\section{(ब) $\odot \otimes$}

This work is licensed under a Creative Commons AttributionNon Commercial 4.0 International License. 